\title{
Should general practice be represented in the university medical school?
}

\author{
MARSHALL MARINKER
}

One of the meanings given to the word "academic" in the Oxford English Dictionary is, "not leading to an answer; impractical." How such a meaning came to be ascribed to a word more understandably associated with the search for answers is beyond the scope of this lecture. But in the English vernacular an academic question is most commonly taken to signify a question for which no answer is worth seeking. In this latter denigratory sense the decision about whether a particular university should have a department of general practice is indeed an academic question. In the United Kingdom today almost without exception the medical school will have a university department of general practice. Indeed, not to have such a department is no longer the hallmark of the traditionalist or the super-technologist, but merely of the quaint.

In the medical school at Leicester general practice is one of the core clinical subjects. The general practice unit is responsible for teaching in every one of the five years of the curriculum, and, (the real gold standard of university life) the subject is independently examined as a component of the final qualifying examination.

Perhaps these political realities should satisfy me, but they do not. A university subject is not created by opening a department, by committing resources, still less by appointing a professor. It

Inaugural Patrick Byrne memorial lecture given at Liverpool on 23 November 1982.

MSD Foundation, Tavistock House, Tavistock Square, London WC1H 9L G

MARSHALL MARINKER, MD, FRCGP, director is created as something more than a response to a political manifesto by asking questions that are truly academic, and trying to find some answers.

\section{Pictures of general practice}

Joanna was 28 years old. Her story was presented to me by a young woman doctor in the course of a seminar on clinical problem solving. The problem concerned the diagnosis and management of what is sometimes called "atypical chest pain." Joanna described a cramping feeling in the middle of her chest, but it was uncertainly related to effort, movement, and posture. The doctors in my small group had all been qualified for about three years: some of them were currently in hospital appointments, others were attached to training general practices. In the course of the case discussion a most rigorous dialectic between the members of the group and the young woman presenting her case failed to discover a likely cause of the pain. Only occasionally would Joanna accommodate her doctor with symptoms that might just possibly suggest an ischaemic heart, or an inflamed gullet, or windpipe, or what have you. The negative results of blood tests, electrocardiograms, and $x$ ray examinations were precisely as unhelpful as negative results always are.

The past medical record showed a recurring theme of anxiety and depression or, to be more precise, a recurring theme of psychotropic drugs in the doctor's responses to Joanna's symptoms. The dcetor reassured her patient that she had found no serious physical cause for her pain, and advised her to rest for a couple of weeks.

At the subsequent consultation Joanna complained miserably that the pain had returned three days before. A further 20 minutes of clinical treasure hunting disclosed no hidden booty. In desperation the doctor said "I want to see you again in a week. Rest at home, do nothing strenuous." With sudden anger 
Joanna turned on the young woman doctor. "You told me to rest two weeks ago. It's pointless. I never do anything at home. Nothing!"

In the seminar discussion that followed the dialectic changed direction. We learnt that Joanna smoked 30 cigarettes a day and continued to take an oral contraceptive. She had had a love affair with one of her husband's colleagues. When her husband found out he threatened to kill himself, and the affair finished. Since then she has had no sex either in or out of her marriage. But she insists she wants to go on taking oral contraceptives, and that she cannot smoke fewer than 30 cigarettes a day.

What is the name of this disease? Who will prescribe an anxiolytic drug or a beta-blocker? How are we to understand the clinical message of a normal electrocardiogram or the bitter "I do nothing at home." And what did it matter that the young woman doctor was attractive, professionally successful, and very pregnant?

I find it difficult to imagine a more challenging clinical problem in the whole of medicine than that presented by Joanna. And yet her story is no less than a commonplace of general practice.

It was once fashionable, perhaps in some circles it still is, to describe general practice as a "sorting office" for patients with undifferentiated illness. As for the rest of the general practitioner's task, this might be seen as an act of containment. Symptomatic responses, the placebo use of highly active drugs, the placebo consultation for those illusions of illness that cannot match the hard realities of contemporary bioengineering.

Such a description was not meant to flatter. But at once it states and it obscures an important truth. The clinical tasks of the general practitioner teasingly resemble those of his colleagues in the hospital. Sometimes that resemblance is actual, sometimes it is imagined: the difficulty, and the challenge for those of us concerned with educating the future general practitioner, is to distinguish between the superficial resemblance and the deep.

Already in trying to explore the nature of general practice I have referre 1 many times to medicine in the hospital. In doing so my intention was to remind you of how influential the teaching hospital has heen in shaping our medical education, and hov' powirful it cont nues to be as a reference for how we behave in general practice.

If you took the renal unit from your own teaching hospital here in Liverpool and transported it to Paris or Tokyo, furnishing ii with the same equipment, and staffing it with the same doctors, it would quickly function in a perfectly normal way. Many things would be similar in the two places. The sort of clinical problems that would face the Liverpool doctors in Paris or Tokyo would be essentially familiar even if the morbidities might have a local bias. The technology would be the same. Perhaps most important of all the philosophy would be the same. The assumptions about what constitutes a rational, humane, and appropriate renal medicine would be no different in the two locations.

But the same would not be true of general practice. You could not translate a Liverpool health centre to a Paris suburb and assume that the matrix of symptoms, beliefs about these symptoms, expectations about health care, and so on would be the same for the Parisian patient as they would be for patients back home. The medicine of general practice has to be most closely applied to the configuration of the culture which it serves.

And yet, though a university subject may properly be concerned with something as limited in space and time as the effect of early English railroads on urban development, the ideas that such a subject articulates must always be universal. The case of Joanna was presented to me in September not in London or Liverpool but in another country.

So I come back to my academic question. Is general practice something more than hospital medicine carried out as best we can in the face of a population most of whom simply will not comply-will not suffer from the required diseases. Are we general practitioners doing something other than practising in a disadvantaged professional environment (the community itself) which does not allow us the time and space for that orderly observation of symptoms and that penetrating pursuit 3 of further evidence that characterises modern medicine in the $\stackrel{\square}{\Omega}$ hospital ward?

\section{What constitutes the idea of "a subject"?}

What constitutes the idea of "a subject" ? Certainly no one $\mathrm{T}$ in the university would deny the title subject to a particular $\because$ language-say, French. I would guess that the professor of $\overrightarrow{\bar{B}}$ French, in defending his territorial boundaries, would make the $\overline{0}$ following sort of statement-though they are of course my own unschooled guesses of what he might say.

The French language is a particular example of the develop- $\bar{\Phi}$ ment of the romance languages from their classical archetype. Because, compared with English, French is a relatively "pure" language, its precision of meaning and the richness of its $\overrightarrow{0}$ expression must be looked for first and foremost in the develop- $\vec{A}$ ment of its grammar, and in particular of its style. In this it $\sigma^{\omega}$ will differ from a language such as English, which is "impure," which has borrowed words and components of words from an astonishing variety of other languages and cultures. If the study $\mathbb{O}^{\circ}$ of French is grounded in an appreciation of style and form the study of English would be grounded in an examination of words $\mathcal{E}$ and their semantic overtones.

The literature of France allows the professor of French not only to focus a lens on the development of a particular society, $\mathrm{G}$ its assumptions, its mores, and its economy. It allows him to $\mathrm{J}$ study the development of particular schools of thought in $\vec{N}$ European philosophy. In this the language has imposed on 3 French philosophy a value system and a habit of reasoning that may be subtly but importantly different from that shown in the $\mathcal{O}$ study of German or Italian.

I was taught that Heinrich Heine never understood, because he was not a "proper" German, that he had spent his life trying to write French romantic poetry in the wrong language. Heineo should be canonised as the patron saint of academic general practice.

The professor of French will have described a unique area of concern. Within that he will be able to specify the content of $\varrho$ his subject. He will be able to point out how far that content $\overrightarrow{\overrightarrow{0}}$ overlaps that of other subjects-for example, other language 3 subjects in the university-and how much belongs exclusively to his own area of study. From such statements he can make two crucial further claims. Firstly, the way in which his subject is taught differs not only in content but in the style of teaching and in the preferred methods of discussion and analysis that areo predicated by the content. Secondly, the nature of his subject 3 . demands a particular form of research which is uniquely fitted $\delta$ to the subject it explores.

The vascular surgeon would certainly be able to answero affirmatively, in the same way as the professor of French, to the

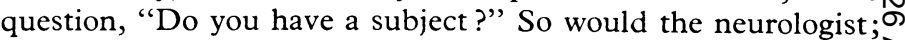
so would the oncologist. But what about the general practitioner? ?

I propose that an academic subject should fulfil the following four criteria.

(1) It should have a unique content capable of accurate $\mathbb{N}^{N}$ description.

(2) It should have preferred methods of teaching that aree dictated by its content.

(3) It should have a methodology uniquely developed to $\stackrel{\oplus}{+}$ explain its content.

(4) It should in consequence of the first three criteria develop a language to describe itself, to encompass the boundaries of its imagination.

In this paper I will not address the second of my criteria General practice has developed its ideas about teaching with 0 greater verve and imagination than most other clinical subjects. But the remaining three criteria require closer scrutiny.

If general practice is nothing more than the application of the knowledge, skills, and attitudes that belong primarily to the? 
major medical specialties whose practitioners continue to be responsible for most of our teaching, then it is not a subject. It is simply a place where medicine is practised. And its practitioners are not medical scientists, they are simply technicians and craftsmen. And those who expound general practice are not teachers, they are simply trainers. What is the truth of the matter?

\section{Do we have a specific content capable of accurate description?}

There is a long tradition of recording morbidity in British general practice, which has produced impressive evidence about the frequency with which different sorts of illnesses are met by doctors in the community, and we can relate these to base populations, so that we may calculate crude measurements of incidence and prevalence.

It was indeed such differences concerning numbers which constituted an early and powerful argument for the introduction of general practice into the medical school. The student would be able to see that acute appendicitis was a common disease in the surgical ward but rare in general practice. Further, the clinical course of these diseases is most often seen in the hospital ward at some point of crisis. For the most part by the very act of admission to a hospital ward, the diagnosis, or at least the possibility of a disease diagnosis, is already predicted. Experience in general practice had therefore to be added to experience in the hospital ward (so went the argument) because the hospital was not able to function as a proper sample of community morbidity.

I have never thought that this was a particularly convincing argument. Teachers in the hospital have never laid claim to a valid sample of community morbidity. On the contrary, the teaching hospital was explicitly constructed in order to be a museum of morbid pathology.

The patient in the hospital, because his symptoms were so florid, because his disease was either so complex or so severe, constituted the "ideal" teaching material. It was in working with these extreme models that the student would gain proficiency in techniques that later would serve him well with less promising material-for instance, with patients not in possession of all the required symptoms and signs, in less advantaged surroundings - that is, the real world. The argument, seen from the point of view of the teaching hospital, is not unreasonable. In this sense, therefore, general practice's claim to show a unique distribution of diseases is not a sufficiently persuasive argument for academic status.

Much more challenging and revolutionary is the notion that what is different about the content of general practice concerns not the frequency with which different diseases will be seen, nor even the different stages in the course of events which may be encountered outside the hospital. These are important desiderata, but they are not enough. It is the quality of what is seen that is different. In what sense do I mean this?

Classic diseases are abstracts, not concrete realities. They are useful because they help the doctor to predict either the course of the patient's unique condition or the likely outcome of the treatments he selects. Yet they remain abstractions. Their power and importance relates largely to the current language that medical scientists find useful. Most convincingly they articulate what Thomas Kuhn' ${ }^{1}$ would call a contemporary paradigmthose models of disease that doctors today find useful.

Nor are they immutable. When heart disease was relatively unamenable to medication but could at least be finally visualised in the postmortem room, the detection of valvular lesions predominated in medical education. So much store was set on detecting a precordial thrill or straining the ear to hear the low rumble of distant diastolic thunder. Later, with the invention of specific drugs that could influence the action of the heart muscle, it was the physiological diagnosis of heart failure that became most important. The anatomical one, unamenable to modifica- tion, was only of interest as an explanation. With the advent of open heart surgery, once again the location of valvular lesions becomes important, and new techniques are developed to identify them. Who will care about valvular lesions when the biochemists teach us to grow new hearts from our own cells, and the surgeons show that exchanging them is as routine as a dental capping ?

The technical preoccupations of medical science today are such that even these brief transports into the world of science fiction fail to dislocate our credulity. What I have described is believable, because I have done no more than articulate and extend the paradigms of medical science that currently preoccupy us. But what of those conditions, those symptoms and signs that do not accord with what is described in the classic texts?

Sometimes they are described as failures of diagnosis. What do we mean by this ? Is it not true that such failures of diagnosis are simply failures of language, failures on the part of the medical profession to find a way of describing what we see, what we recognise, and what we already know about clinical courses and the likely outcomes of treatment? How is the clinician to react when his observations and experiences are not made coherent by theory, or even by written precedent and case law ?

Rose aged 45 has had four children. She comes from a Roman Catholic family and moved from Belfast to Leicester when she was still an adolescent. Two years ago she developed heavy periods, was admitted to hospital with a severe haemorrhage and a haemoglobin of $5 \mathrm{~g} / \mathrm{dl}$. The gynaecologist found some small fibroids in an otherwise normal uterus and performed an emergency hysterectomy. Since then she has been sleepless, has lost her libido, and suffers from crippling vasomoter instability. Drug treatment has always been unsatisfactory in her case, though she now takes regular small doses of diazepam.

What is the diagnosis? What is the name of the disease for which an emergency hysterectomy was regarded as the treatment of choice? Rose says, "I certainly did not want to have any more children. When I realised what they had taken away from me, I cried as though I had lost a baby." Of course, the nosologies of gynaecology and psychiatry have some ways of describing the illness of Rose, and general practice persists in borrowing this language, even though its poverty to describe and explain continues to frustrate.

Doctors are said to look for two sorts of explanation in medicine. They seek causative explanations that lead to an understanding of the diagnosis and they seek management explanations that allow a prediction to be made about the usefulness of remedies. The attempt to develop a whole person medicine approach to general practice has so far been relatively weak in providing causative explanations. But by contrast it has been relatively strong in providing management explanations.

For the moment general practice may do well to leave causative explanations to those who give them best-the hospital based specialists who work on the boundary between laboratory science and clinical manifestations. In contrast, we general practitioners who work on the boundary between clinical manifestations and the idiosyncratic life of our individual patients have already developed a mode of inquiry that addresses the management decisions which we take with patients such as Joanna and Rose. These mysterious management decisions seem to work for our patients, even though we ourselves cannot understand why they work or even why we have chosen them.

I do not want to suggest that this uniqueness of content, this different quality of medicine of which I speak, yet amounts to a nosology that can describe the not uncommon events in Rose's history. Indeed, general practice continues to show itself willing to use the descriptions of gynaecology and psychiatry, while all the time indicating in its rhetoric and in its teaching that it uses these terms with reservations, or even with disdain. We hint that the detailed and the anecdotal stories that we can tell about our patients refer to some yet undiscovered nosology that will bring together at one and the same time the physical component of the patient's illness-the fibroid uterus and the exsanguination 
-and the psychological component-the patient's feeling that her uterus was essential to her female identity-and the social component-for example, the effect of her present feelings on the way in which her family functions. Such a field theory of medicine, however, is I am afraid more to be found in the rhetoric of general practice than in the reports of empirical research.

\section{Is there a unique research of general practice?}

Is there a unique research of general practice? Perhaps this is the most crucial question of all. A subject is constituted by its research, and this research in turn determines the boundaries and configurations of the discipline. It is the way in which we research that determines the nature of general practice, and unless our research can match the imagination of our rhetoric, general practice will remain only a political force in medicine and not an intellectual one. It is here that I believe that the claim of general practice to be an academic discipline is most vulnerable. Whereas in teaching we have been quick, even eager, to innovate, as researchers we continue to be fettered by beliefs and customs outside our own experience. For these reasonsthat our methodologies continue to be borrowed inappropriately from specialist medicine, that we are afraid to take risks-we may fail to extend the narrow boundaries of our knowledge.

If you look at the record of general practice research in the United Kingdom over the past 20 years you will find that most work consists of epidemiological descriptions of work load, incidence of morbidity, and so on. Almost all studies have used epidemiological methods. Research in general practice has been largely operational research, though there are many important and valuable exceptions to the rule.

By its very nature this sort of research concerns itself with the accurate measurement of a tiny number of variables in populations. Because this form of epidemiology is geared to examine health care systems, the variables chosen for measurement become increasingly predictable-in addition to age and sex, there are social class, family size, major morbidities, frequency of attendance, items of medication, absence from work, and so on.

It is in the nature of epidemiology that the individual experience must be expressed in terms of base populations, that incidence and prevalence are important, not simply events. The occurrence of an event achieves an importance that is first and last a statistical significance-a relation between the unique event, other similar events, and the size of the population within which they occur. I describe this as being true for epidemiology, but it is true also for the bioengineering research of the clinical biologist. Indeed, we have medical specialisms today precisely because medical research has enforced on practising doctors a special preoccupation with a few clinical variables.

The paradox for general practice research, so anxious to prove itself respectable in the respected world of the medical scientist, is that the medicine which it experiences, and the experience of illnesses which it confronts, seem to many of us to lie outside the grasp of current scientific methodology. Why is this?

General practice claims to integrate at one and the same time the physical, the psychological, and the social. In more recent years the rhetoric of general practice has been much given over to ways of looking at "the whole person." And yet all science pulls us away from such universalist preoccupations. Day to day research is not about universal truths but about particular ones. It seems impossible at one and the same time to look at the patient who has chest pain in terms of her cardiac function, her feelings, and the cultural matrix within which she knows her symptoms. Is it then impossible for us to research in a way which is consonant both with the way in which we practise and the way in which we teach ? It is my contention that if we give a positive answer to this question, if we cannot research what we practise and teach, then we do not have a subject, we simply have a handful of strategies for responding in a totally pragmatic way to those problems that proper medicine, specialist medicine, has not yet been able to elucidate. In this sense we are a branch $\underset{\underline{m}}{z}$ of medicine surviving from a previous age, and we are allowed $\$$ to continue until such time as biotechnology and behavioural $\stackrel{2}{c}$ science are able finally to relegate us to an honourable place in $\bar{\Omega}$ the history of medicine. Those of us who are not ready for such $\overline{\bar{J}}$ honourable retirement must be prepared to look again at the nature of scientific research, and we need to ask ourselves some $\mathbb{\infty}$ difficult questions about what constitutes scientific truth.

The view taken by the general practitioner of his patient has? to be a rounded one. The patient's story is unique to the patient $\overrightarrow{\overrightarrow{\vec{p}}}$ himself, and the natural history is inexplicably bound up with the history of the disease and of the individual. Without such a view, no personal medicine, personal in the sense that general $\frac{\bar{O}}{\bar{N}}$ practice regards as central to its philosophy, would be possible. $\frac{\widehat{\sigma}}{\sigma}$ The variables that medical science chooses to measure, such as $\unrhd$ the ones to which I referred above, or biotechnical measurements, or physiological responses, these are in the end a matter of $\overrightarrow{0}$ fashion. They are dictated by those research enterprises that, at a time when the work is being carried out, have yielded exciting $\vec{\omega}$ or promising results. It is this type of research activity, using $\frac{S}{\partial}$ established methodologies, measuring variables in a more or 3 . less acceptable field, that Thomas Kuhn describes as "normalin science." A scientific revolution occurs, non-normal science occurs, when the methodology and the variables that it articulates $\mathcal{E}^{\circ}$ no longer produce useful answers. The paradox with which we are now faced is that while current methodologies and variables $\infty$ produce brilliant results in the clinical laboratory of the teaching $\mathcal{G}$ hospital, or in the large community populations studied by음 clinical epidemiologists, they do not sufficiently elucidate those $\overrightarrow{\vec{N}}$ medical problems such as those I mentioned above, and which ${ }_{N}^{N}$ constitute such a large component of the general practitioner's encounters with his individual patients.

On some fronts, therefore, general practitioner researchers $\underset{\vec{S}}{\vec{S}}$ may have much to discover if they retreat from the disciplines of numeracy which, often in the past, have offered them only. the illusion of precision. In the University of Leicester IO organised such a retreat from measurement to narrative with a group of eight general practitioners, a clinical epidemiologist, a sociologist, a clinical psychologist, and an anthropologist. We took as our subject of study women who came to their doctors $\stackrel{\mathbb{Q}}{\mathbb{2}}$ because of disordered menstruation, and who then underwent $\stackrel{2}{\overrightarrow{2}}$ hysterectomy. Patterns of feelings, expressions, and irrational 3 behaviour (both by patient and doctor) began to emerge from the stories we followed. The work of model building was slow? - a hypothesis burgeoned at one meeting to be dismembered by the narrative of the next two cases. Twelve years earlier 1 had been a member of Balint's research group on patients who. received repeat prescriptions. The same sequence of reluctant $\frac{5}{3}$ inquiry and unpredicted findings surprised us at every turn.

There is no shame in going back to naked natural history. The work of Sydenham, Graves, Addison, Bright, and MacKenzie are there to light the way. But if we cannot yet rely on statistics 5 to tell us how likely it is that our hunches are going to pay off, N we have to look for other rigorous checks and balances to keep our observations honest. Increasingly the video camera is replacing the anecdote, and some researchers are experimenting with health diaries to stiffen our clinical impressions. Research in general practice in the future may make claim to high quality ${ }_{\sigma}^{\omega}$ by standards very different from those acknowledged by our colleagues in other clinical disciplines. In some of the modes of our research we may find ourselves closer to the historian, the linguist, and the archeologist than to the natural scientist.

\section{An academic question}

It is an academic question, a question now hardly worth asking let alone answering, whether general practice should beo represented in the university medical school. The unique content of general practice, at least in terms of numbers, cannotô. be denied. So much of the teaching, so much of the recently? published research is clearly recognisable to all of our clinical 
colleagues, and it is of a respectable quality. But in this lecture I have tried to emphasise what is new, what is perhaps strange in general practice for those who do not have a direct experience of its clinical work.

Perhaps it is to my fellow academics in departments of general practice that I am making my most earnest plea for disreputable adventure.

I must warn you that what $I$ have presented in this lecture in no way constitutes a consensus view of my subject, or of where it is going. If the imagination of the academic general practitioner does not reflect his own clinical experience, but only the clinical expectations of others, he will contribute nothing to medicine but the dry rustling of a career bibliography.

While general practice remained outside the university it drew its strength from its direct confrontation with the patient's complaint and the doctor's response. Its weakness lay in the absence of any disciplined exegesis of what was going on. Such disciplined exegesis constitutes the life and breath of the university experience. The danger for general practice, for medicine, and for the care which the patients will receive is that this new university subject may trade adventure, risk taking, and innovation for respectability. It remains to be seen. That is a truly academic question.

\section{Reference}

${ }^{1}$ Kuhn T. The structure of scientific revolutions. Chicago: Chicago University Press, 1962.

(Accepted 31 fanuary 1983)

\section{MATERIA NON MEDICA}

\section{In search of Alfred Wallis}

We must have looked quite a strange trio in the pouring rain as we searched the graveyard overlooking St Ives. It was a grey and dismal day with no respite from the weather as we continued our search for the resting place of a simple Cornishman, Alfred Wallis. Wallis had been a fisherman all his life, often sailing in windjammers to Newfoundland, who took to painting for the first time at the age of 73 during his retirement. He painted maritime scenes on anything that he could lay his hands on, including wood, cardboard, leather, stone jars, newspaper, and even his kitchen table. Paintings of ships, lighthouses, and harbours were often distorted to fit into the odd shapes of cardboard supplied by the local greengrocer.

Wallis was discovered in August 1928 by Ben Nicholson and Christopher Wood, both young men then, who happened to look into his parlour while walking down a back street in St Ives, curiously named Back Street. The primitive paintings inspired the young artists and they brought Wallis a wide circle of admirers. What then is his appeal? Some authors have said that his feeling for texture came from a lifetime of handling rough materials at sea and others have attributed a haunting quality present in his work to his deeply held religious beliefs (he would cover up his paintings with newspaper on Sundays). This may all be true, but for me it is the clarity with which he observed the changing moods of the sea that makes him so special. Wallis continued to paint until his death in the poorhouse at Madron in 1942, at the age of 87 . Sadly, most of his paintings have now been destroyed, but examples of his work have been exhibited in both London and New York.

A shout from the far corner of the graveyard brought a timely end to our search. We were now all soaked to the skin, but the grave of the old fisherman was found. The tombstone lies flat and the whole surface is composed of tiles in earthy autumnal colours designed and fired by the master of ceramics, Bernard Leach. Each tile is different yet fits perfectly with its neighbour to build a picture of a lighthouse, a traditional welcome for sailors safely home from sea. At its base is the simplest of epitaphs, "Alfred Wallis, Artist and Mariner." - MICHAEL HUMPHRIES, London.

\section{A special place}

I rediscovered the loch almost by accident. I'd visited it once, while I was still a student, but hadn't so much as thought of it for five years until I found myself living nearby. One cold April day, with guests to entertain and nowhere of note yet open to the early spring tourists, we took a run there on the off chance that the short-eared owls I'd seen before would be as obliging again. We walked along the loch-side road, muffled against the biting wind. In due course we found an owl quartering the hillside above us; our hands were so cold that we could hardly hold the glasses, but the bird was unconcerned by us and flew low overhead. Later on we saw two together, sparring in mid-air in the early dusk, silent like outsized moths.

As the light faded, we almost missed the day's star prize. In the gloom, a pair of red-throated divers flew in and would have gone in the book as cormorants had they not started "hoo-hooing" to each other. Another visitor told us that he had seen them there before, and we drove home with the smugness that comes of having made a difficult diagnosis and being proved right.

In the weeks that followed we went back many times. I was looking for a practice to join after my vocational training, and my wife was carrying our first child. As the pile of refusal letters grew ever higher, and our spirits sank ever lower, we found in our loch a place where we could unwind; often we would go on the spur of the moment, taking a picnic rather than sitting down to a meal at home. We only once failed to see a bird of note, and that, inevitably, was when we took some other friends to show them our peregrines, owls, and cuckoos.

Out of the blue, a phone call, a hurried journey south, handshakes all round and a dramatic rise in my credit rating.

In the weeks that followed my appointment, we were too busy to go to the loch for a while. When eventually we did get there again, it was a dull, dreich, grey, drizzly day, and we sat in the car eating our lunch, looking down on the loch through the rain-splattered windscreen. There was a splash, and through the rain I saw a large, heavy bird fly up from the water. I lost it as I jumped out of the car, but sweeping round the loch with my glasses I found a bird that produced instant sinus tachycardia; big, brown above, pale below, rather stiff-winged and flying over a secluded loch, it had to be an osprey. Another joined it and the pair flew the length of the loch above us, silhouetted against the sky before eventually dropping low enough for us to see their colours. Later, a third bird appeared, probably one of last year's young or an unpaired bird, but the pair paid it little attention and it drifted off alone. We lost them all then, and were on the point of going when a single bird reappeared and gave us a virtuoso display of fishing.

We went back only a few times after that. Once, we saw the osprey fishing briefly, but never again had the long views of that first occasion. Once, I pointed it out to some other visitors-a foolish thing to do, since you never know what other people will do with the knowledge of the whereabouts of rare birds; they were polite but uninterested, which was just as well. The fewer people who know, the better for the birds, and the better for the birds, the better for the people who know.LINDSAY J C EASTON, general practitioner, Lincoln.

\section{Correction}

\section{Is serum $\gamma$-glutamyltransferase a misleading test ?}

In the paper by Drs R Penn and D J Worthington (12 February, $p$ 531) the first sentence of the conclusions should have read: "In the face of the widely varying factors that influence serum $\gamma$-glutamyltransferase values, it is surprising that $\gamma$-glutamyltransferase estimations have not lost popularity for differential diagnosis among clinicians, even though it is one of the most sensitive indicators of hepatobiliary disease." 